\title{
放射光特性を生かした角度分解光電子分光研究
}

\author{
堀場 弘司・組頭 広志 \\ 高エネルギー加速器研究機構物質構造科学研究所フォトンファクトリー 函 305-0801 茨城県つくば市大穂 1-1
}

（2017 年 6 月 20 日受付；2017 年 7 月 25 日掲載決定）

\section{Angle-Resolved Photoemission Spectroscopy Utilizing Characteristics of Synchrotron Radiation}

Koji Horiba and Hiroshi Kumigashira

\begin{abstract}
Photon Factory, Institute of Materials Structure Science, High Energy Accelerator Research Organization,
\end{abstract}
1-1 Oho, Tsukuba, Ibaraki 305-0801

(Received June 20, 2017 ; Accepted July 25, 2017)

\begin{abstract}
Angle-resolved photoemission spectroscopy (ARPES) is a powerful experimental tool for revealing the electronic band structure of solids. Excellent characteristics of synchrotron radiation light enable us to achieve specialized ARPES measurements. In order to perform such experiments, we have constructed a new beamline BL-2 MUSASHI (Multiple Undulator beamline for Spectroscopic Analysis of Surface and Hetero-Interface) at Photon Factory, KEK. As examples of the specialized ARPES measurements by utilizing the advantage of this beamline, we introduce recent ARPES results on ( 1 ) three-dimensional electronic structures with changing the photon energy, (2) bulk electronic structures using high energy soft x rays, and ( 3 ) orbital-selective electronic structures by polarization dependent ARPES measurements.
\end{abstract}

KEYWORDS : synchrotron radiation, angle-resolved photoemission spectroscopy, electronic structure

\section{1.は じめに}

角度分解光電子分光 (Angle-Resolved Photoemission Spectroscopy : ARPES）は, 固体表面のバンド構造を直 接決定する非常に強力な実験手法であり，これまで表面 科学研究において多大な貢献を果たしてきたことは, 今 さらいうまでもないことであろう。ARPES 実験の技術 は日々発展を続けており, たとえば実験室系 ARPES 装 置で用いられる励起光源一つを取ってみても, 従来広く 用いられていた He 放電管の高分解能化に始まり, Xe ガスの利用による低エネルギー化とさらなる高分解能 化 ${ }^{1)}$ ，また近年では高調波レーザーを用いた超高エネル ギー分解能 ${ }^{2}$ やフェムト秒オーダーの時間分解能の達 成 ${ }^{3)}$ な゙，その進歩はとどまるところを知らない。この ような進歩を受けて多様化していく ARPES 研究の中 で，他の実験室系光源にはない優れた特性を持つ放射光 は, 様々な特徵的な ARPES 実験を可能とし, その果た

E-mail : horiba@post.kek.jp
す役割もますます大きくなっている。本稿では，このよ うな特徵的な ARPES 実験を行うために, フォトンファ クトリーにおいて建設された新ビームライン BL-2 MUSASHI と,そこで行われたいくつかの先端的 ARPES 研究の事例について紹介する。

\section{2. 放射光源の特性を生かした ARPES 研究}

まず放射光源の特性と, それを励起光源とした場合に 可能となる光電子分光の特長について簡単にまとめた い。一般的に放射光源の特性としては, 広いエネルギー 範囲の連続光であること, 高い指向性, パルス性, 偏光 特性, などがあげられる。これらの特性を生かして可能 となる, 実験室光源にはない特徽的な ARPES 実験とし て考えられるものには, 以下のようなものがあげられ る。

(1) 励起エネルギーを広範囲で走査して ARPES 測定が 可能である。ARPES においては, 励起エネルギーを変 化させることで試料表面に垂直方向の波数を変化させる ことができるため, 励起エネルギーの走査により試料表 
面に垂直方向の波数におけるバンド分散を得ることがで きる4)。また, 各元素の原子軌道に扔ける光励起断面積 が励起エネルギーにより異なるため ${ }^{5)}$, 最適なエネルギ 一を選択することで, 観測対象となる特定の軌道のバン ドを強調することができる。

(2) 通常の実験室光源を利用したARPES と比較して, より高エネルギーの軟 X 線を励起光として用いること が可能である。放出される光電子の脱出梁さはその運動 エネルギーに依存し, 高エネルギー領域では運動エネル ギーが高くなるほど光電子の検出長を大きくすることが 可能である4)。したがって, 高エネルギーの軟 X 線を励 起光源とするARPESでは, 埋もれた界面や物質内部の バンド構造を観測することができる。

(3) 近年では放射光を発生させる挿入光源の発展によ り，任意の偏光（水平・垂直・左右円）を持つ放射光を 発生させることや, 同一光源において偏光を切り替えた りすることが可能となっている。ARPES 測定において は, 原子軌道の対称性による選択則やスピン偏極などに より, 励起光の偏光に応じて光励起断面積が変化す る ${ }^{6}$ 。このため, 異なる偏光を励起光源とする ARPES 測定を行うことにより, 軌道選択的なバンド構造を観測 することや，バンドのスピン偏極に関する情報を得るこ とが可能である。

このほかにも, 高い指向性を生かした微小スポットサ イズ化による微小試料の測定や面内空間分布測定，パル ス性を生かした時間分解測定などがあげられる。

\section{3. 先端的 ARPES 研究のための放射光ビーム ラインーBL-2 MUSASHI-}

フォトンファクトリーでは，このような放射光の特長 を生かした様々な先端的 ARPES 実験を行うために, 新 しいビームライン BL-2 を建設し, 共同利用実験に供用 を行っている。Fig. 1 にビームラインの概略図を示す。 このビームラインは Multiple Undulator beamline for Spectroscopic Analysis of Surface and Hetero-Interface （MUSASHI）と名付けられ, その最も大きな特徵は, 異 なる 2 台のアンジュレータ挿入光源をタンデムに配置 し, 実験に応じてアンジュレータを切り替えて利用する ことが可能となっている点である。この 2 台のアンジュ

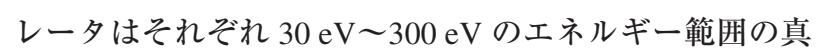
空紫外光用と, $250 \mathrm{eV} \sim 2000 \mathrm{eV}$ の高エネルギー軟 X 線 用となっている。したがってこの 2 台のアンジュレータ を切り替えることで, 非常に広いエネルギー範囲の放射 光を利用することが可能であり, 前述した11の励起エネ ルギーを走查した ARPES 穾験や，(2)の高エネルギー軟 X 線を利用した ARPES 実験などが可能となっている。

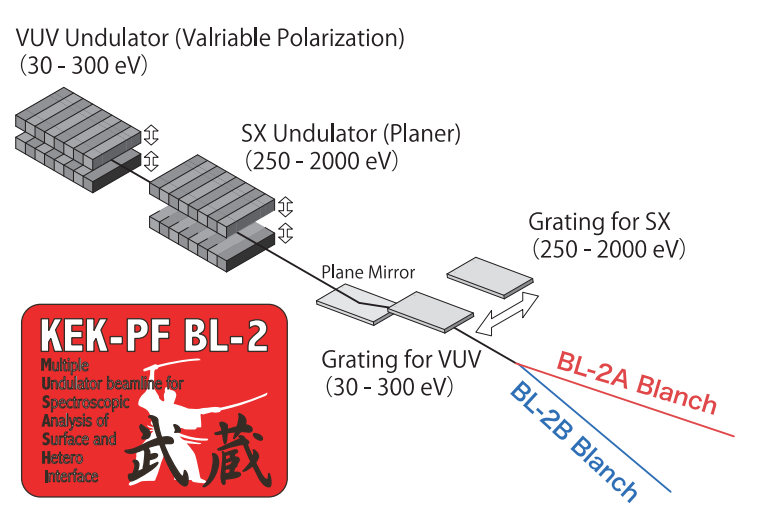

Fig. 1. (color online). Schematic layout of BL-2 MUSASHI beamline. (a) VUV region

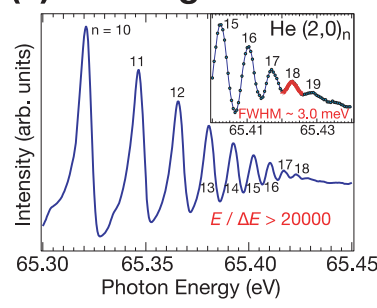

(b) SX region

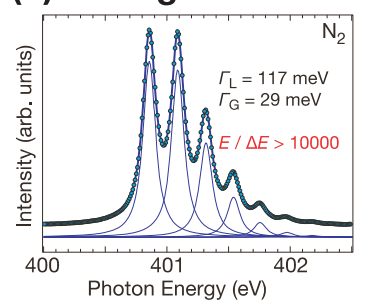

(c) Photon Flux

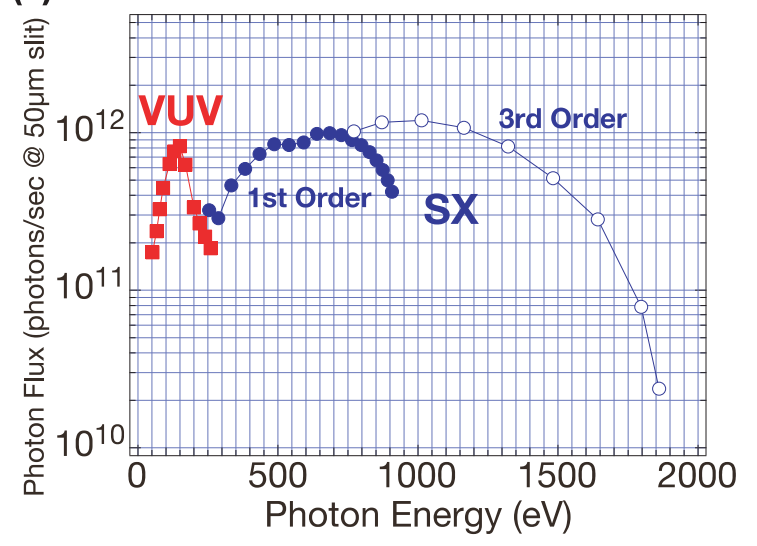

Fig. 2. (color online). Performance of BL-2 MUSASHI beamline. The photoionization spectra of (a) He in VUV region and (b) $\mathrm{N}_{2}$ molecules in SX region. (c) Photon flux in VUV and SX regions measured with a Si photodiode.

さらに真空紫外用のアンジュレータは, 磁石列の配置に より水平・垂直・左右円偏光すべてのモードを切り替え て使用することが可能であり，これを用いて(3)の偏光依 存性 ARPES 実験を行うことも可能となっている。

Fig. 2 に BL-2 MUSASHI の光源性能評価の結果を示 す。光源のエネルギー分解能は希ガスの励起スペクトル により評価を行っている。真空紫外光領域では Fig. 2 (a) に示す $65 \mathrm{eV}$ 付近の $\mathrm{He}$ 励起スペクトルにより，エ 
ネルギー分解能 $E / \Delta E>20000$ を達成し, また軟 $\mathrm{X}$ 線領 域では Fig. 2（b）に示す $400 \mathrm{eV}$ 付近の $\mathrm{N}_{2}$ 励起スペク トルのほか, $250 \mathrm{eV}$ 付近の $\mathrm{Ar}$ 励起スペクトル, $870 \mathrm{eV}$ 付近の $\mathrm{Ne}$ 励起スペクトルなどで評価した結果, これら のエネルギー領域すべてで $E / \Delta E>10000$ を達成してい ることがわかった。また Fig. 2 (c) にはフォトダイオ ードにより測定したフォトンフラックスを示す。真空紫 外光から軟 $X$ 線に渡る非常に広いエネルギー領域で, ARPES 測定のために十分なフラックスが得られている ことがわかる。

このような光源性能を持つ BL-2 MUSASHI のエンド ステーションとして, A ブランチには ARPES 装置とレ ーザー分子線エピタキシー（Laser MBE）装置とが超高 真空で接続された「in situ ARPES-Laser MBE 複合装 置7)」（Fig. 3）が常設されている。放射光を利用した ARPES 実験において, 励起エネルギー走查による試料 表面に垂直方向のバンド分散測定という手法が特徽的な 実験の一つであることは既に述べたが，この手法が必要 となる物質群というのは, 当然のことながら面直方向に バンド分散を持つものであり, すなわち 3 次元的な電子 構造を有する物質ということになる。このような物質に おいては䢃開面を持たない物質も多いため, 清浄な単結 晶表面を得るためには, 超高真空中で表面が原子レベル で制御された単結晶薄膜試料を作製し，その表面を大気 に曝すことなく in situでの ARPES 測定を行う必要があ る。したがって，このような薄膜試料の in situ ARPES 測定というのは放射光源との相性が非常に良い。

なお, ビームラインの B ブランチには特に常設装置 を設けないフリーポートエリアがあり，ユーザーが他の

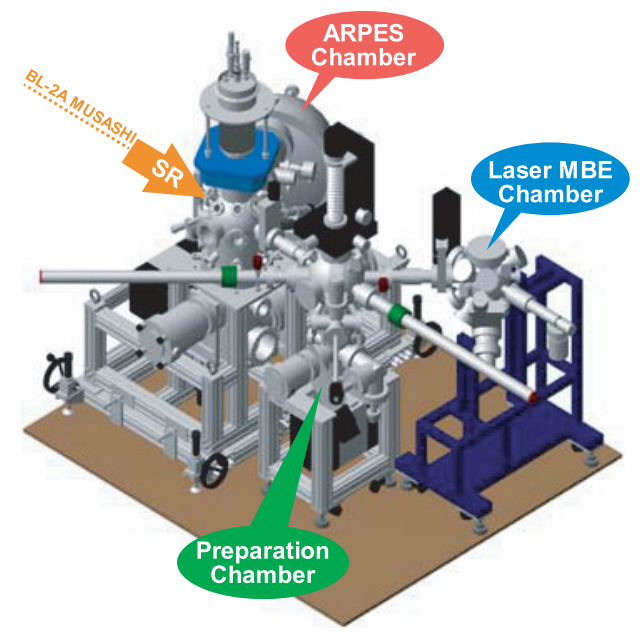

Fig. 3. (color online). Schematic illustration of "in situ ARPES-Laser MBE system” at BL-2 MUSASHI beamline.
特徵的な測定装置を持ち込んで実験を行うことも可能と なっている。

\section{BL-2 MUSASHI を用いた先端的 ARPES 研 究事例}

4.1 励起エネルギー走査を利用した研究例 一 $\mathrm{La}_{0.6} \mathrm{Sr}_{0.4} \mathrm{MnO}_{3}$ 薄膜の 3 次元的電子状態とキ ンク構造 ${ }^{8}$

ここからは BL-2 MUSASHI を用いた実際の研究事例 についていくつか紹介したい。まず，励起エネルギーを 走査した ARPES 測定を利用した研究例として，ペロブ スカイト型 $\mathrm{Mn}$ 酸化物 $\mathrm{La}_{0.6} \mathrm{Sr}_{0.4} \mathrm{MnO}_{3}$ （LSMO）薄膜の in situ ARPES の結果について紹介する。LSMO はほぼ立 方晶で近似できるような 3 次元的な結晶構造および電子 状態を有するため, 良く定義された表面を持つ単結晶薄 膜試料の in situ ARPES 測定と励起エネルギー走査によ る面直方向バンド分散の測定が本質的に重要となる系で ある。

Fig. 4 (a) に LSMO のブリュアンゾーンと, 面直方 向の波数の対称点において予想されるフェルミ面形状の 模式図を示す。 $\Gamma X M$ 面内においては $\Gamma$ 点周りの小さな 電子面が存在し, 面直波数の異なる ZRA 面内において は A 点周りに大きなホール面が存在することが予想さ

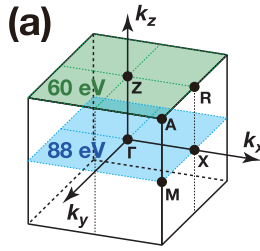

(b) $88 \mathrm{eV}$

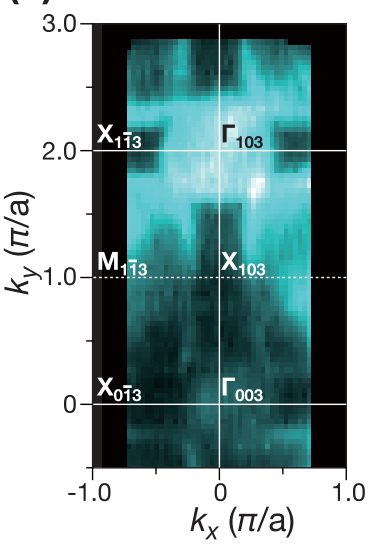

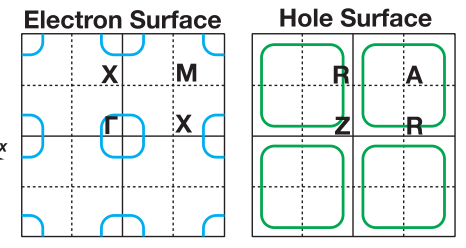

(c) $60 \mathrm{eV}$
Fig. 4. (color online). (a) Schematic illustration of the Brillouin zone and the expected Fermi surface (FS) of LSMO films. (b) FS mapping for photon energies of $88 \mathrm{eV}$ corresponding to the ГXM plane and (c) $60 \mathrm{eV}$ corresponding to the ZRA plane. 
れる。このような電子構造について，実際に ARPES に よりフェルミ面を測定した結果を Fig. 4（b）および

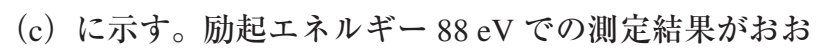
むね「XM 面のトレースに対応し, 一方励起エネルギー $60 \mathrm{eV}$ での測定が扔抒むね ZRA 面のトレースに対応し ている。まず異なる励起エネルギーの測定結果におい て, 得られたフェルミ面形状に大きな変化が見られるこ とから, 励起エネルギー走查により面直方向のバンド分 散に起因する変化が得られていることがわかる。特に, 理論計算により予測されるフェルミ面形状と比較する と, 励起エネルギー $88 \mathrm{eV}$ では $\Gamma$ 点周りの電子面が, 励起エネルギー $60 \mathrm{eV}$ では $\mathrm{A}$ 点周りに大きなホール面 が観測されていることがわかる。

このように 3 次元的な電子構造を有する物質において は, 励起エネルギー走查により測定している面直方向の 波数を正確に規定することで, 特定のフェルミ面を形成 しているバンド分散の詳細な解析が可能となる。Fig. 5 にホール面を形成するバンド分散を詳細に解析した結果 を示す。Fig. 5（b）に示すように，エネルギー方向と波 数方向の 2 次元マッピングとして得られた ARPES スペ クトルについて, 波数方向のピーク位置をフィッティン グにより求め, それをエネルギー方向にプロットするこ とによりバンド分散を決定した。その結果, このバンド 分散には $50 \mathrm{meV}$ 付近にキンク構造が存在することを見 いだした。このキンク構造は, Fig. 5 (a) に示すような ホール面の様々な位置でバンド分散を測定した結果, Fig. 5 (c)-(g) に示すようにホール面全体に等方的に存 在することがわかった。このことは局在したモードとの
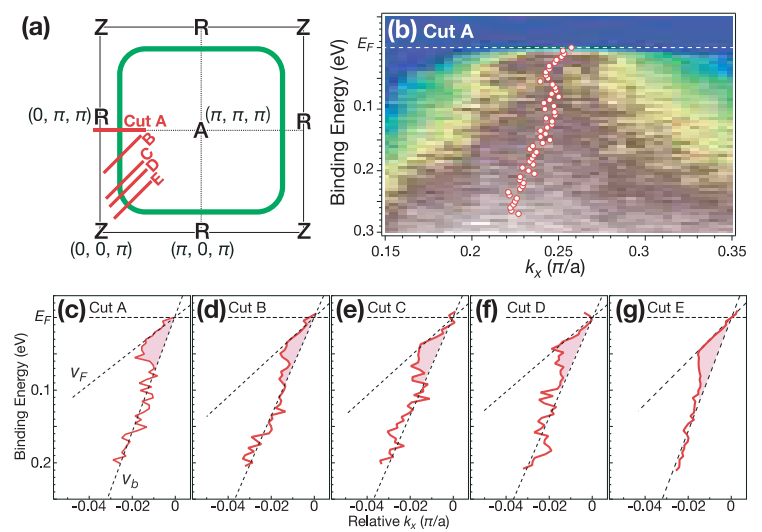

Fig. 5. (color online). (a) Schematic illustration of the hole Fermi surface, together with the measurement cuts A-E. (b) Intensity map for the band dispersion along the Cut A. Open circles indicate the peak positions of momentum distribution curves (MDCs). (c) - (g) Band dispersions obtained from the MDCs along cuts A-E, respectively.
相互作用を示唆しており，エネルギー位置からヤーンテ ラーフォノンとのポーラロン的な相互作用によるものと 考えられる。

\section{2 高エネルギー軟 X 線を利用した ARPES 研究例 -2 次元エレクトライド物質 $\mathrm{Y}_{2} \mathrm{C}$ におけるエレ クトライドバンドの直接観測 ${ }^{9)}$}

次に高エネルギーの軟 X 線を利用したバルク電子状 態観測の研究例として, 2 次元エレクトライド物質 $\mathrm{Y}_{2} \mathrm{C}$ についての結果を紹介する。2 次元エレクトライドと は, 近年 $\mathrm{Ca}_{2} \mathrm{~N}^{10)}$ やこの $\mathrm{Y}_{2} \mathrm{C}^{11)}$ において発見された新し い電子状態を有する新物質群である。その結晶構造は通 常の 2 次元層状化合物と同様であるが, 通常の 2 次元化 合物の場合には 2 次元伝導を担う電子は層状の結晶格子 内に存在している（Fig. 6 (a)）のに対して, 2 次元エ レクトライドに拈いては Fig. 6 (b) に示すように, 層 状結晶格子が正電荷を持ち, そのカウンターとなる負イ オンの代わりに電子が層間に存在しており，この層間電 子が 2 次元伝導を担う。このような物質について ARPES 測定を行う場合を考える。通常の 2 次元層状化 合物においては擘開表面に露出した結晶格子内の電子状 態を測定すればよいので, 表面敏感な ARPES 手法でも 本質的な情報を得ることが可能である。一方で, 2 次元 エレクトライド電子は表面の結晶格子に埋もれた下部層 に存在するために, この電子状態を観測するためにはバ ルク敏感な ARPES 手法が必須となる。

これを踏まえて，この特異な電子状態を示す 2 次元エ レクトライド物質である $\mathrm{Y}_{2} \mathrm{C}$ について, 高エネルギー の軟 X 線を用いてエレクトライド電子のバンド構造を 詳細に観測した結果を Fig. 7 に示す。この案験において も，励起光のエネルギーを選択することにより面直方向 のフェルミ面を測定し, その対称点が存在する励起光エ (a) Ordinary 2D material

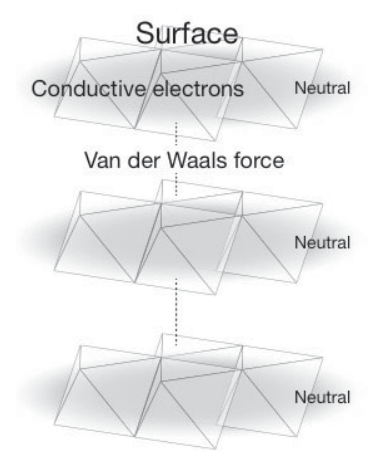

(b) 2D electride

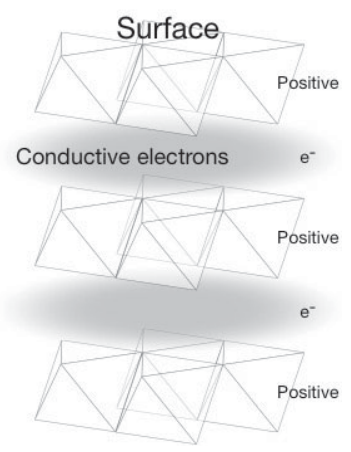

Fig. 6. Schematic illustration of the crystal and electronic structures of (a) ordinary two-dimensional (2D) materials and (b) in case of $2 \mathrm{D}$ electride materials. 
(a)

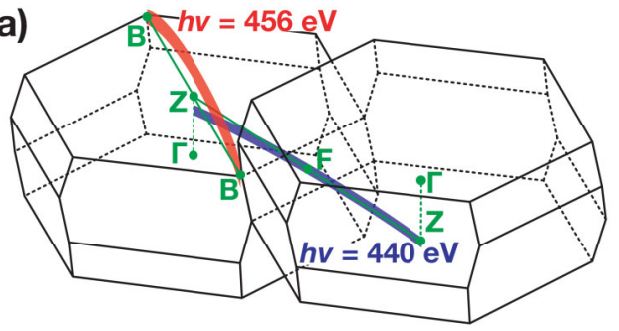

(b) $h v=440 \mathrm{eV}$

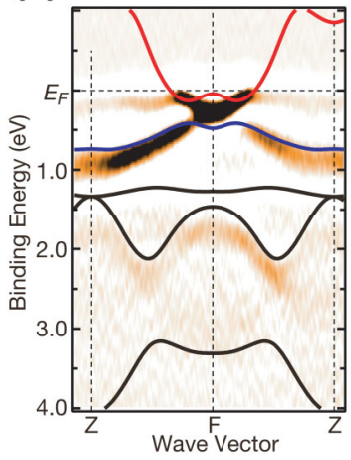

(c) $h v=456 \mathrm{eV}$

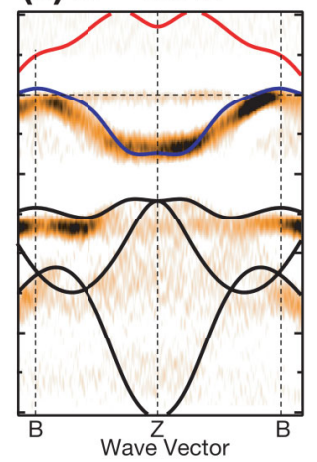

Fig. 7. (color online). (a) Brillouin zone for the rhombohedral lattice of $\mathrm{Y}_{2} \mathrm{C}$ and $k$-paths for which ARPES measurements were carried out. (b) Experimental band structures measured at $h \nu=440 \mathrm{eV}$ and (c) at $h \nu=456 \mathrm{eV}$. The energy bands along the Z-F-Z and B-Z-B directions calculated by the FLAPW method are superimposed by solid lines, respectively.

ネルギーから，観測している面直方向の波数を規定して いる9)。Fig. 7 (a) に示す $\mathrm{Y}_{2} \mathrm{C}$ のブリュアンゾーンにお いて, 励起エネルギーと試料の面内方向の角度を変化さ せることにより，励起エネルギー $440 \mathrm{eV}$ で $\mathrm{F}$ 点周りの バンド構造を, 励起エネルギー $456 \mathrm{eV}$ で B 点周りのバ ンド構造を観測した結果をそれぞれ Fig.7（b)，（c）に 示す。理論計算では $\mathrm{F}$ 点の周りには小さな電子面, $\mathrm{B}$ 点 の周りに小さなホール面が, それぞれエレクトライド電 子由来で形成することが予想されているが，ARPES で 観測されたバンド構造は，この理論計算の結果と非常に

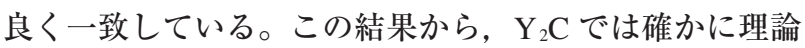
計算どおりの 2 次元エレクトライド状態が実現している ことが証明された。

\section{3 偏光依存 ARPES による軌道選択的バンド構造 の研究例一 $\mathrm{SrVO}_{3}$ 薄膜}

最後に励起光の偏光を制御した ARPES 測定により, バンドを構成する原子軌道の対称性を分離して観測でき るということを示す例として, $\mathrm{SrVO}_{3}$ 薄膜における実験 結果を紹介する。 $\mathrm{SrVO}_{3}$ はV $3 d t_{2 \mathrm{~g}}$ 軌道に電子が一つ存 在する電子構造をとる。(001) 表面に扔ける $t_{2 \mathrm{~g}}$ 軌道の対 称性は, Fig. 8 (a) に示すようになっており，ここに励 起光を入射した際の入射方向や偏光べクトルの方向と原
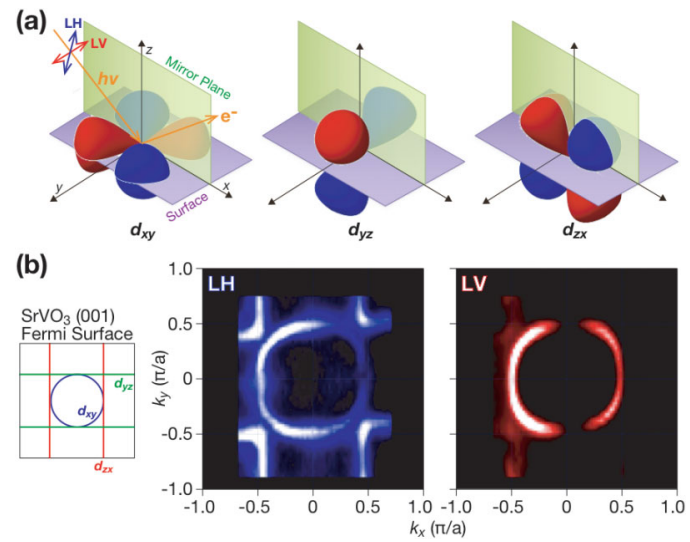

Fig. 8. (color online). (a) Schematic illustration of the configuration of experimental setup and $t_{2 \mathrm{~g}}$ orbitals of $\mathrm{SrVO}_{3}$ (001) surface. (b) Schematic illustration of the expected Fermi surface of $\mathrm{SrVO}_{3}(001)$ surface and the measured Fermi surface using synchrotron light with linear horizontal (LH) and linear vertical (LV) polarizations.

子軌道の対称性の関係などから, 双極子選択則により導 かれる遷移行列要素により, 各軌道の光励起断面積に差 が生じる6)。特に励起光の偏光を光源の制御により変化 させることができれば，それ以外の実験配置を一切変化 することなく偏光べクトルの対称性のみを変えることに 対応するため, バンド構造の軌道対称性を分離・選択す る手法として非常に有用である。Fig. 8（b）には実際に 偏光を水平偏光 (Linear Horizontal : LH) と垂直偏光 (Linear Vertical : LV) にした場合の ARPES によるフェ ルミ面の観測結果を示す。予想されるフェルミ面と比較 すると, 偏光べクトルを変えることにより, 特定の原子 軌道から構成されるフェルミ面の強度が変化しているこ とがわかる。このようにして, 複数のバンドが複雑に重 なり合うような系においても，偏光を選択して特定のバ ンドのみを強調し, その電子構造を詳細に解析すること が可能となる ${ }^{12)}$

なお，我々が現在用いている ARPES 装置では，この ようなフェルミ面を取得する際に試料を回転する必要が あるが，その際に測定面と鏡映対称面にずれが生じるた めに, 遷移行列要素を厳密に決定することは困難であ る。最近試料を回転させることなく 2 次元波数空間のマ ッピングを行うことができる新型の光電子分析器が開発 されて扮り，これを用いることでより正確な軌道対称性 の議論が可能となる。現在フォトンファクトリーでもこ のような新型の ARPES 装置を立ち上げ中である。

\section{5. を め}

本稿では, 放射光源の特長を生かした ARPES 研究と 
して, 励起光エネルギー走查による表面垂直方向の波数 に扔けるバンド分散測定, 高エネルギー軟 X 線を利用 したバルク敏感バンド分散測定, 偏光依存性による軌道 刘称性分離バンド分散測定, の三つの研究事例について 紹介した。これらの測定手法のさらなる発展のために は, 光源の高度化も必要不可欠である。特に本稿では述 べなかった微小スポット光源による面内の空間分解測定 などは, その性能が光源の輝度に直結するような測定手 法であるため, 次世代の高輝度放射光源の実現が望まれ るところである。

\section{謝 辞}

本稿で紹介した研究は, 高エネルギー加速器研究機構 組頭研究室のメンバーである, 小林正起特任助教（現東 京大学大学院工学系研究科准教授), 簧原誠人特別助教, 湯川龍研究員, 北村未歩研究員, 連携大学院生 (東北大 学大学院理学研究科) の三橋太一氏, 志賀大亮氏らとと もに行ったものである。また KEK-PF BL-2 MUSASHI ビームラインの建設は, 高エネルギー加速器研究機構の 雨宮健太教授, 柳下明名誉教授, 北島義典講師, 豊田智 史研究員 (現京都大学大学院工学研究科助教), 豊島章 雄氏, 田中宏和氏, 菊地貴司氏, 森丈晴氏, 斉藤裕樹 氏, 濁川和幸氏, 永谷康子氏, 小菅隆氏らの協力を得て 行った。 $\mathrm{La}_{0.6 \mathrm{~S}} \mathrm{Sr}_{0.4} \mathrm{MnO}_{3}$ 薄膜の ARPES 研究は, 高エネル ギー加速器研究機構の吉松公平研究員 (現東京工業大学 大学院理工学研究科助教), 坂井延寿研究員 (現東京大 学大学院工学系研究科助教), 東京大学大学院理学系研 究科の藤森淳教授らとの共同研究である。 $\mathrm{Y}_{2} \mathrm{C}$ の $\mathrm{AR}-$ PES 研究は高エネルギー加速器研究機構の村上洋一教 授, 物質 - 材料研究機構の井下猛氏 (現東京工業大学元 素戦略研究センター特任教授), 大谷茂樹氏, 大橋直樹 氏, 東京理科大学の浜田典昭教授, 東京工業大学元素戦 略研究センターの真木祥千子研究員 (現広島大学助教), 山浦淳一特任准教授, 細野秀雄教授らとの共同研究であ る。これらの方々に感謝申し上げる。本研究の一部は文 部科学省「元素戦略プロジェクト [研究拠点形成型 $]$ 電 子材料領域 東工大元素戦略拠点 (TIES)」および科学
研究費（B25287095，16H02115，16K05033）の支援を 得て行われた。本研究は高エネルギー加速器研究機構放 射光実験共同利用課題（PF-PAC 2013S2-002，2015S2005，2012G536，2012G688）として行われた。

\section{文献}

1) T. Sato, S. Souma, K. Sugawara, K. Nakayama, S. Raj, H. Hiraka and T. Takahashi : Phys. Rev. B 76, 113102 (2007).

2) K. Okazaki, Y. Ota, Y. Kotani, W. Malaeb, Y. Ishida, T. Shimojima, T. Kiss, S. Watanabe, C.-T. Chen, K. Kihou, C.H. Lee, A. Iyo, H. Eisaki, T. Saito, H. Fukazawa, Y. Kohori, K. Hashimoto, T. Shibauchi, Y. Matsuda, H. Ikeda, H. Miyahara, R. Arita, A. Chainani and S. Shin : Science 337, 1314 (2012).

3) Y. Ishida, T. Togashi, K. Yamamoto, M. Tanaka, T. Kiss, T. Otsu, Y. Kobayashi and S. Shin : Rev. Sci. Instrum. 85, 123904 (2014).

4) S. Hüfner : "Photoelectron spectroscopy : Principles and applications” (Springer, Berlin, 2003).

5) J.J. Yeh and I. Lindau : At. Data Nucl. Data Tables 32, 1 (1985).

6) A. Damascelli, Z. Hussain and Z.-X. Shen : Rev. Mod. Phys. 75, 473 (2003).

7) K. Horiba, H. Ohguchi, H. Kumigashira, M. Oshima, K. Ono, N. Nakagawa, M. Lippmaa, M. Kawasaki and H. Koinuma : Rev. Sci. Instrum. 74, 3406 (2003).

8) K. Horiba, M. Kitamura, K. Yoshimatsu, M. Minohara, E. Sakai, M. Kobayashi, A. Fujimori and H. Kumigashira : Phys. Rev. Lett. 116, 076401 (2016).

9) K. Horiba, R. Yukawa, T. Mitsuhashi, M. Kitamura, T. Inoshita, N. Hamada, S. Otani, N. Ohashi, S. Maki, J. Yamaura, H. Hosono, Y. Murakami and H. Kumigashira : Phys. Rev. B 96, 045101 (2017).

10) K. Lee, S.W. Kim, Y. Toda, S. Matsuishi and H. Hosono : Nature 494, 336 (2013).

11) X. Zhang, Z. Xiao, H. Lei, Y. Toda, S. Matsuishi, T. Kamiya, S. Ueda and H. Hosono : Chem. Mater. 26, 6638 (2014).

12) T. Mitsuhashi, M. Minohara, R. Yukawa, M. Kitamura, K. Horiba, M. Kobayashi and H. Kumigashira: Phys. Rev. B 94, 125148 (2016). 